\title{
A novel drying process for oil adsorption of expanded graphite
}

\author{
Soo-Jin Park ${ }^{1, \star}$, Seul-Yi Lee ${ }^{1}$, Ki-Seok Kim ${ }^{1}$ and Fan-Long Jin ${ }^{1,2}$ \\ ${ }^{1}$ Department of Chemistry, Inha University, Incheon 402-751, Korea \\ ${ }^{2}$ Department of Polymer Materials, Jilin Institute of Chemical Technology, Jilin City 132022, People's Republic of China
}

\section{Article Info}

Received 3 May 2013

Accepted 27 June 2013

*Corresponding Author

E-mail: sjpark@inha.ac.kr

Tel: $+82-32-8767234$

\section{Open Access}

DOI: http://dx.doi.org/

10.5714/CL.2013.14.3.193

This is an Open Access article distributed under the terms of the Creative Commons Attribution Non-Commercial License (http://creativecommons.org/licenses/ by-nc/3.0/) which permits unrestricted non-commercial use, distribution, and reproduction in any medium, provided the original work is properly cited.

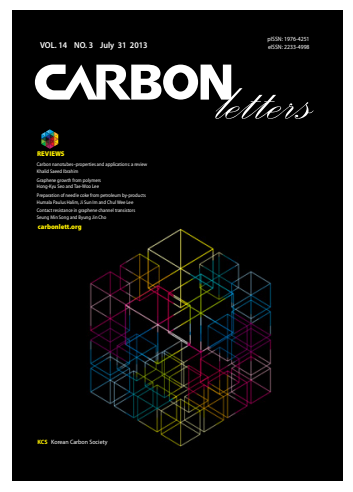

http://carbonlett.org

pISSN: $1976-4251$

elSSN: 2233-4998

Copyright $\odot$ Korean Carbon Society

\begin{abstract}
Expanded graphite (EG) was prepared using a drying process for application as an oiladsorbent: the morphology, expansion volume, and oil absorption capacity of the EG were investigated. The expanded volume of the EG increased with an increasing reaction time and heat treatment temperature. The oil adsorption capacity of the EG was $45 \mathrm{~g}$ of n-dodecane per $1 \mathrm{~g}$ of EG. It is noted that the drying process of EG is a useful technique for a new oiladsorbent.
\end{abstract}

Key words: expanded graphite, drying process, morphology, oil adsorption capacity

\section{Introduction}

Expanded graphite (EG) is a well-known carbon material that is usually produced from various graphite intercalation compounds (GICs). The process of GIC exfoliation may be undertaken using chemical, electrochemical, and thermal methods. EG maintains layered structures similar to natural flake graphite, but it has differences in the distances between the graphite layers. As a new carbon material, EG has been used in many fields, such as gaskets, seals, batteries, substratum for adsorption, etc. Among these applications, its potential as an adsorbent for heavy oil has attracted significant attention due to the surprisingly high adsorption capacity of EG for various oils [1-7].

Toyoda and Inagaki [8] studied the adsorption behaviors of exfoliated graphites using four types of heavy oils. The results indicated that the maximum adsorption capacity of $1 \mathrm{~g}$ of exfoliated graphite was as high as $86 \mathrm{~g}$ of A-grade heavy oil or $76 \mathrm{~g}$ of crude oil. Zheng et al. [9] investigated the adsorption capacity of exfoliated graphite for oil-sorption in and among worm-like particles. Their results demonstrated that the adsorption capacities of the pores in and among the worm-like particles increased with increases in the exfoliation volume.

In this study, EG was prepared using a new drying process for oil-adsorbent materials, and its morphology, expansion volume, and oil absorption capacity are investigated.

\section{Experimental}

\subsection{Materials}

The graphite used in this study was supplied by GRAF Guard ${ }^{\mathrm{TM}}(>297 \mu \mathrm{m}$, flake graphite). Oleum $\left(25 \% \mathrm{SO}_{3}\right)$ was used as an intercalant, and n-dodecane was purchased from Sigma (Korea).

\subsection{EG preparation}

The GICs were prepared using the direct reaction of graphite with oleum gas in atmospheric conditions. In order to intercalate $\mathrm{SO}_{3}$ in the graphite layers, $\mathrm{SO}_{3}$ gas was vaporized through 
heating the oleum at $120^{\circ} \mathrm{C}$ and passing it through an upper flask filled with graphites. The GICs were dried at $90^{\circ} \mathrm{C}$ for $8 \mathrm{~h}$ in order to remove the $\mathrm{SO}_{3}$ molecules condensed on the graphite surfaces. The EG was obtained through heat treatment of the dried graphite particles at $900^{\circ} \mathrm{C}$ for $1 \mathrm{~min}$.

\subsection{Characterization and measurements}

The morphology of the EG was examined using a scanning electron microscopy (SEM; JXA 840A, JEOL, Japan). The expansion volume was calculated from the EG volumes before and after the heat treatment. The oil adsorption tests were conducted via direct addition of the graphite to the oil. The EG was added to a mixture of water and oil. It was then dried on an 80 $\mu \mathrm{m}$ sieve in order to remove the non-aborted oil and moisture. The oil adsorption was calculated using the following equation:

$$
\text { Oil adsorption }=\frac{m-m_{0}}{m_{0}},
$$

where $m_{0}$ and $m$ are the weight of EG before and after the adsorption, respectively.

\section{Results and Discussion}

Fig. 1 presents a SEM image of the EG. As seen from this image, there were numerous carbon layers with large interlayer distances, which were formed as a result of the heat treatment of the GICs at a sufficiently high temperature. Furthermore, the EG had a loose and porous vermicular structure. The structure of the EG appeared to have parallel boards and it exhibited many pores with different sizes $[10,11]$.

Fig. 2 presents the expanded volume of the EG as a function of the reaction time. The expanded volume of the EG increased significantly with an increasing reaction time up to $10 \mathrm{~h}$. When the reaction time was increased, the graphite layers opened gradually due to the oxidizing agent, and the molecules of the inserting reagent entered the graphite layers, which resulted in the formation of a large amount of GICs. Thus, the expansion volume of the EG increased rapidly [12].

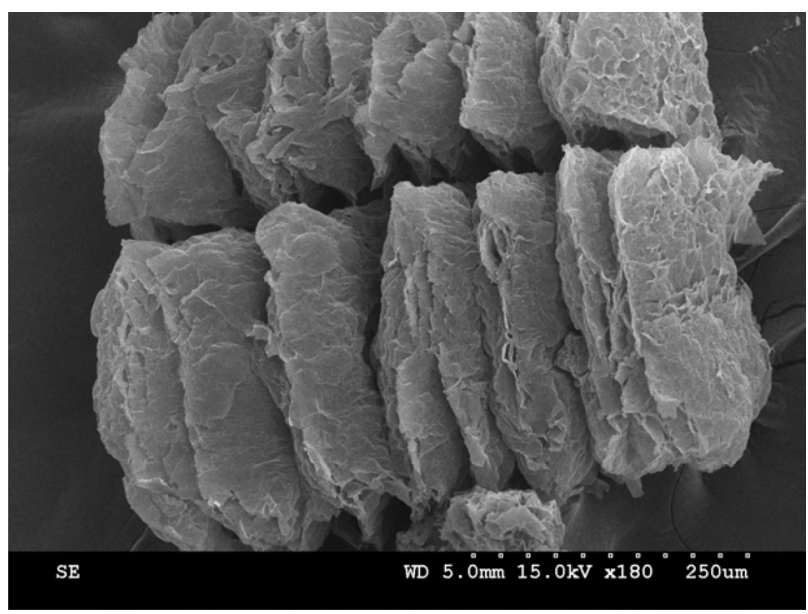

Fig. 1. Expanded graphite morphology.
Fig. 3 presents the expanded volume of the EG as a function of the heat treatment temperature. When the heat treatment temperature increased, the expanded volume increased gradually with the maximum expanded volume being achieved at $900^{\circ} \mathrm{C}$ and the expanded volume decreasing over $900^{\circ} \mathrm{C}$. This can be attributed to the expanded GIC needing energy; however, some carbon began to combust over $900^{\circ} \mathrm{C}$ [12].

Fig. 4 shows the oil adsorption capacity of natural graphite and EG for n-dodecane. The oil adsorption tests indicated that the n-dodecane was absorbed rapidly by the EG. The oil adsorption capacity of EG (45 g of n-dodecane per $1 \mathrm{~g}$ of EG) was significantly higher than that of natural graphite. These results can be attributed to the EG having surface characteristics that consist of micropores and macropores, which induce the capillary phenomenon between the particles and pores on the surface of the EG and result in an increasing oil adsorption capacity $[13,14]$.

In this work, EG was prepared using a drying process for potential application as an oil-adsorbent. The morphology,

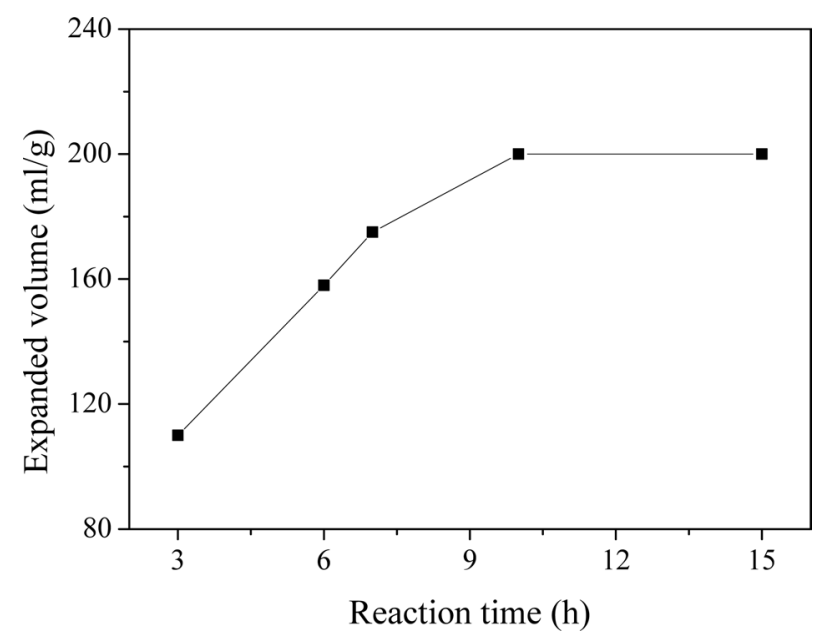

Fig. 2. Expanded volume of the expanded graphite as a function of the reaction time.

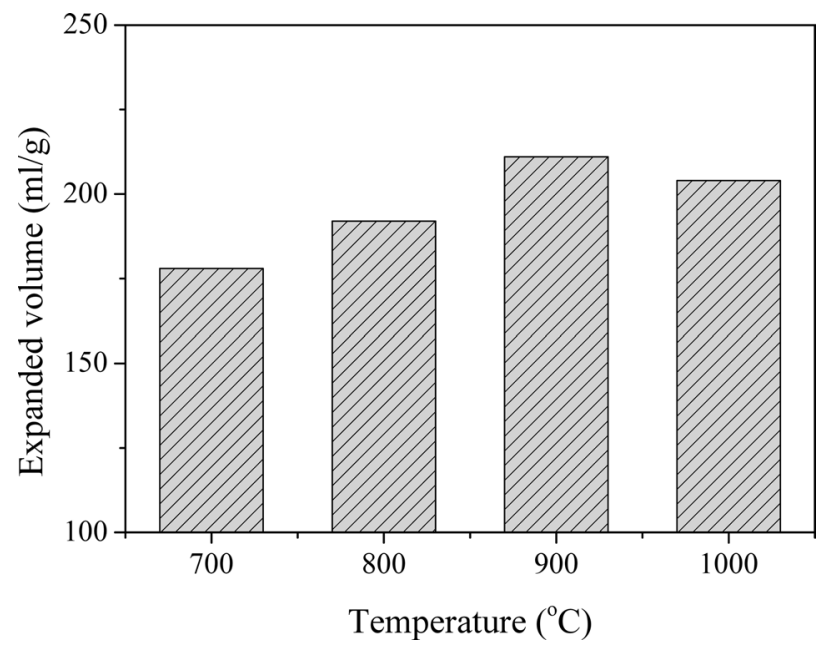

Fig. 3. Expanded volume of the expanded graphite as a function of the heat treatment temperature. 


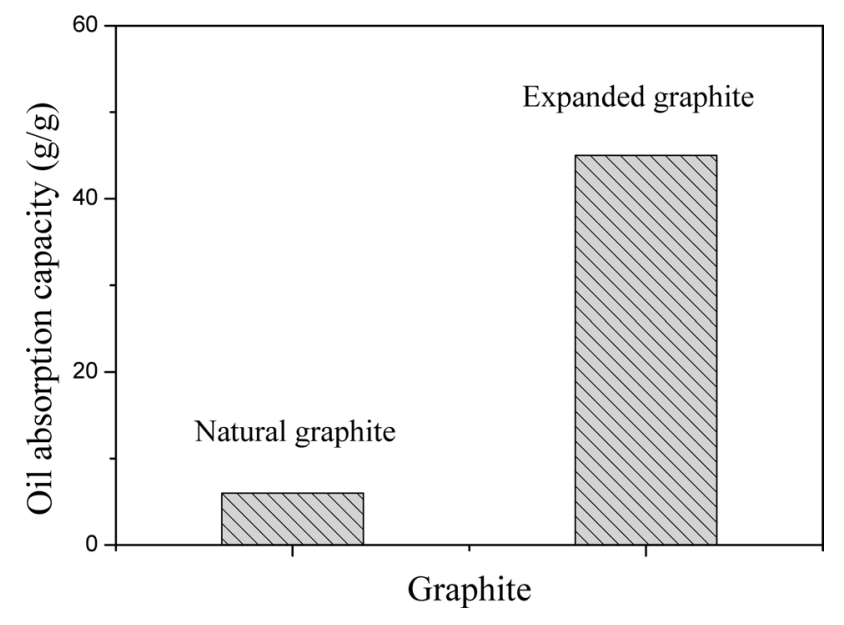

Fig. 4. Oil adsorption capacities of natural graphite and expanded graphite for n-dodecane.

expansion volume, and oil adsorption capacity of EG were investigated. As expected, the expanded volume of the EG increased with an increasing heat treatment temperature up to $900^{\circ} \mathrm{C}$. The oil adsorption capacity of EG was $45 \mathrm{~g}$ of n-dodecane per $1 \mathrm{~g}$ of EG. The data reported in this study suggests that EG has excellent properties and is a promising candidate for oiladsorbent applications.

\section{Acknowledgements}

This work was supported by the Korea CCS R\&D Center (KCRC) grant funded by the Korea government (Ministry of Science, ICT and Future Planning) (grant No. 0031985).

\section{References}

[1] Balima F, Pischedda V, Le Floch S, Brulet A, Lindner P, Duclaux L, San-Miguel A. An in situ small angle neutron scattering study of expanded graphite under a uniaxial stress. Carbon, 57, 460 (2013). http://dx.doi.org/10.1016/j.carbon.2013.02.019.

[2] Dittrich B, Wartig KA, Hofmann D, Mulhaupt R, Schartel B. Flame retardancy through carbon nanomaterials: carbon black, multiwall nanotubes, expanded graphite, multi-layer graphene and graphene in polypropylene. Polym Degrad Stab, 98, 1495 (2013). http://dx.doi.org/10.1016/j.polymdegradstab.2013.04.009.

[3] Park SJ, Kim KS. A study on oil adsorption of expanded graphites. Korean Chem Eng Res, 42, 362 (2004).

[4] Park SJ, Kim KS, Hong SK. Preparation and characterization of expanded graphites by wet process. Hwahak Konghak, 41, 802 (2003).

[5] Ajalesh Balachandran N, Philip K, Rani J. Effect of expanded graphite on thermal, mechanical and dielectric properties of ethylene-propylene-diene terpolymer/hexa fluoropropylene-vinylidinefluoride dipolymer rubber blends. Eur Polym J, 49, 247 (2013). http://dx.doi.org/10.1016/j.eurpolymj.2012.08.014.

[6] Sever K, Tavman IH, Seki Y, Turgut A, Omastova M, Ozdemir I. Electrical and mechanical properties of expanded graphite/high density polyethylene nanocomposites. Composites B, 53, 226 (2013). http://dx.doi.org/10.1016/j.compositesb.2013.04.069.

[7] Piana F, Pionteck J. Effect of the melt processing conditions on the conductive paths formation in thermoplastic polyurethane/expanded graphite (TPU/EG) composites. Compos Sci Technol, 80, 39 (2013). http://dx.doi.org/10.1016/j.compscitech.2013.03.002.

[8] Toyoda M, Inagaki M. Heavy oil sorption using exfoliated graphite: new application of exfoliated graphite to protect heavy oil pollution. Carbon, 38, 199 (2000). http://dx.doi.org/10.1016/S00086223(99)00174-8.

[9] Zheng YP, Wang HN, Kang FY, Wang LN, Inagaki M. Sorption capacity of exfoliated graphite for oils-sorption in and among wormlike particles. Carbon, 42, 2603 (2004). http://dx.doi.org/10.1016/j. carbon.2004.05.041.

[10] Wang LW, Tamainot-Telto Z, Metcalf SJ, Critoph RE, Wang RZ. Anisotropic thermal conductivity and permeability of compacted expanded natural graphite. Appl Therm Eng, 30, 1805 (2010). http://dx.doi.org/10.1016/j.applthermaleng.2010.04.014.

[11] Krawczyk P. Effect of ozone treatment on properties of expanded graphite. Chem Eng J, 172, 1096 (2011). http://dx.doi. org/10.1016/j.cej.2011.06.005.

[12] Jihui L, Huifang D, Qian L, Shufen L. Preparation of sulfur-free expanded graphite with $320 \mu \mathrm{m}$ mesh of flake graphite. Mater Lett, 60, 3927 (2006). http://dx.doi.org/10.1016/j.matlet.2006.06.066.

[13] Li S, Tian S, Du C, He C, Cen C, Xiong Y. Vaseline-loaded expanded graphite as a new adsorbent for toluene. Chem Eng J, 162, 546 (2010). http://dx.doi.org/10.1016/j.cej.2010.05.059.

[14] Li S, Tian S, Feng Y, Lei J, Wang P, Xiong Y. A comparative investigation on absorption performances of three expanded graphitebased complex materials for toluene. J Hazard Mater, 183, 506 (2010). http://dx.doi.org/10.1016/j.jhazmat.2010.07.052. 